\title{
REGULATION OF PHOSPHATASE HOMOLOGUE OF TENSIN PROTEIN EXPRESSION BY BONE MORPHOGENETIC PROTEINS IN PROSTATE EPITHELIAL CELLS
}

\author{
Travis J. Jerde, Ph.D. ${ }^{1}$, Zhong Wu, Ph.D. ${ }^{2}$, Dan Theodorescu, M.D., Ph.D. ${ }^{2}$, and Wade \\ Bushman, M.D., Ph.D. ${ }^{3}$ \\ Zhong Wu: ZW2N@hscmail.mcc.virginia.edu; Dan Theodorescu: DT9D@hscmail.mcc.virginia.edu; Wade Bushman: \\ bushman@urology.wisc.edu \\ ${ }^{1}$ Departments of Pharmacology-Toxicology and Urology, Indiana University School of Medicine, \\ Indianapolis, IN 42606 \\ 2Paul Mellon Urological Cancer Institute-University of Virginia Medical School, Charlottesville, VA \\ 22908 \\ ${ }^{3}$ Department of Urology-University of Wisconsin School of Medicine and Public Health-, Madison, \\ WI 53792
}

\begin{abstract}
Background-Phosphatase homologue of tensin (PTEN) is the most commonly mutated gene in prostate cancer. Bone morphogenetic proteins (BMPs) are known to promote differentiation and inhibit proliferation. Previously published reports from other organ systems led us to investigate a mechanistic relationship between PTEN and BMP signaling in prostate epithelial cells.
\end{abstract}

\begin{abstract}
Methods-We analyzed growth rate and PTEN expression in E6, BPH-1 and C4-2B prostate epithelial cells treated with BMP-4. We also treated doxacyclin-inducible PTEN-C4-2B cells with BMP-4 and doxacyclin to determine the effect of BMP on growth and PTEN expression in conditions of increasing PTEN expression. We determined the dependency of BMP-mediated growth inhibition via siRNA knockdown of PTEN expression and BMP treatment. We determined PTEN protein stability by determining the effect of BMP-4 on PTEN protein at time points after treatment with cyclohexamide, a translation inhibitor.
\end{abstract}

Results-We found that BMP-4 induces PTEN in E6 and BPH-1 cells and reduces proliferation. Knockdown of PTEN attenuated the growth-inhibiting effects of BMP-4 in these cells. BMP-4 had no effect in PTEN negative-C4-2B cells, but doxacyclin-driven PTEN C4-2B cells responded to BMP-4 with enhanced PTEN and growth inhibition. BMP-4 also increased PTEN protein stability.

Conclusions-BMP signaling induces PTEN expression and sustains PTEN protein expression resulting in inhibition of prostate epithelial cell growth. These data are the first to identify a mechanistic linkage between BMP signaling and PTEN in the prostate, both of which are independently identified as tumor suppressors and suggest possible coordinate dysregulation in prostate cancer.

Correspondence: Travis J. Jerde, Ph.D., A417 Medical Sciences, 635 Barnhill Drive, Indianapolis, IN 46202, 317-274-1534, Fax: 317-274-7714, tjjerde@iupui.edu .

Disclosure Statement. None of the authors listed have any significant or perceived conflicts of interest relating to the publishing of this manuscript. 


\section{Keywords}

Prostate; epithelium; bone-morphogenetic protein; phosphatase homologue of tensin analogue; protein stability

\section{INTRODUCTION}

Phosphatase homologue of tensin (PTEN) is one of the most commonly associated mutated genes in prostate cancer, and its mutation is tightly correlated to poor clinical prognosis.[1] This protein functions as an endogenous intracellular modulator of the phosphoinositide-3kinase $\left(\mathrm{PI}_{3} \mathrm{~K}\right)$-Akt pathway and therefore plays a central role in regulating proliferation in many epithelial cells.[2] A key regulatory step in this cascade is phosphorylation of phosphoinositide-bisphosphate $\left(\mathrm{PIP}_{2}\right)$ to generate $\mathrm{PIP}_{3}$ by $\mathrm{PI}_{3} \mathrm{~K}$, resulting in activation of phosphoinositide-dependent kinases (PDK) and activation of Akt by phosphorylation.[2] PTEN acts as a phosphoinositide phosphatase to reverse this reaction and inhibit $\mathrm{PI}_{3} \mathrm{~K}-\mathrm{Akt}$ signaling.[2] Therefore reduced expression or function of PTEN in cancer permits unregulated Akt activation and increased tumor cell proliferation.[3-4] Numerous mitogens and cytokines impinge upon this pathway by activating secondary adaptor molecules such as src, focal adhesion kinase (FAK), and insulin-like receptor substrate (IRS) that initiate the $\mathrm{PI}_{3} \mathrm{~K}$-Akt signaling cascade.[5-8]

Studies of growth regulatory pathways in the developing prostate have identified a number of important morphogens including fibroblast growth factors, hedgehog ligands, cytokines including interleukins and transforming growth factor beta, Notch, wnt/beta-catenin and the bone morphogenetic proteins (BMPs).[9] The BMPs are members of the TGF-beta superfamily and over 20 BMP ligands have been identified.[10] The BMPs act by binding heterodimers of BMPR type II and type I receptors activating members of the SMAD family of signaling intermediates, most particularly SMADs 1, 5, and 8.[10] The readout of BMP signaling is phosphorylation of SMADs and changes in transcription of specific target genes. [10] Previous studies have shown that the ligands BMP-4 (and its homolog BMP-2) and BMP-7 are expressed in the developing prostate and exert important effects on prostate growth and proliferation.[11-12] Interestingly, expression of BMP-2, 4, and 7 ligands, BMP receptors and intracellular signaling components is diminished in prostate cancer as compared to normal tissue, and BMPs have been shown to inhibit prostate cancer cell line proliferation and tumor growth.[13-15]

Although it is widely accepted that genetic mutation of PTEN can contribute to tumor tumorgenesis, recent studies suggest regulation of PTEN expression and activity may also contribute to tumor growth.[16] For example, studies have shown that PTEN protein expression is reduced in a significant number of breast cancers.[17] Although, the precise mechanism behind reduced PTEN protein levels in these cancers is poorly understood, repression of PTEN expression as well as changes in the activity and stability of PTEN protein have been proposed. Multiple signals could lead to positive or negative modulation of PTEN expression, including TGF $\beta$ signaling, UV radiation, and EGR-1 and PPAR signaling.[18-19] Interestingly, BMP signaling has been demonstrated to sustain PTEN expression in colon cancer cells.[20,21] Given the concurrent loss of expression of PTEN and BMP commonly observed in prostate cancer, we sought to investigate a possible mechanistic relationship between these pathways. 


\section{MATERIALS AND METHODS}

\section{Cells and culturing conditions}

E6 prostate epithelial cells were kind gifts from Dr. David Jarrard, Department of Urology, University of Wisconsin Madison, and were cultured in conditions as previously published. [22] The immortalized cells were screened for HPV16 E6 protein expression by Western blot analysis and were cultured for over 20 passages to confirm immortality. BPH-1 cells were kindly provided by Dr. Simon Hayward, Vanderbilt University, Nashville, TN and were grown and maintained in conditions previously published.[23] The doxycyclin (DOX)inducible C4-2 primary cell line (C4-2 pTetOn) cells were generated by Dr. Zhong Wu under the supervision of Dr. Dan Theodorescu and have been previously described.[24] Cells were generated by transfection of pTRE2hyg PTEN-HA into C4-2 pTetOn cells; cells were maintained in 10\% FBS/RPMI 1640 medium.

\section{Growth rate determinations}

Equivalent passages within each prostate cell line were plated at 5000 cells/well in 24-well plates. After a 24 hour attachment period, cells were grown in their prescribed media with 0 , 1,10 , or $100 \mathrm{ng} / \mathrm{ml} \mathrm{BMP}-4$ (R\&D systems, Minneapolis, MN) in the presence or absence of $500 \mathrm{ng} / \mathrm{ml}$ noggin (BMP antagonist-BMP and noggin were co-incubated 1 hour prior to addition to the cells to allow for binding). At time 0 and at 24 hour intervals, cell photos of each well were taken at consistent marked locations in quadruplicate. All cell growth experiments were performed 4 times $(n=4)$ for each cell line. Cell numbers were determined for each treatment and are reported as number of cells per 20X field. Each point is the mean \pm S.E.M. of the total cell counts.

\section{Protein extraction, SDS-PAGE, and immunoblotting}

Isolated prostate cells were homogenized in protease inhibitor-containing lysis buffer (150 $\mathrm{mM} \mathrm{NaCl}, 10 \mathrm{mM}$ Tris, $1 \mathrm{mM}$ EDTA, $1 \mathrm{mM}$ benzenesulfonyl fluoride, and $10 \mu \mathrm{g} / \mathrm{ml}$ each of aprotinin, bestatin, L-leucine, and pepstatin A). Triton X-100 was added to a concentration of $1 \%$, and the homogenate was incubated on ice for 60 minutes, followed by centrifugation for $20 \mathrm{~min}$ at $14,100 x \mathrm{G}$ at $4 \mathrm{C}$. The supernatant was collected and total protein concentration was determined by BCA assay (Pierce, Rockford, IL). Proteins (20 $\mu \mathrm{g} / \mathrm{well})$ were resolved by electrophoresis in 4-20\% gradient SDS-polyacrylamide electrophoresis gels. Proteins were transferred to PVDF membranes, blocked overnight $[10 \mathrm{~g} / \mathrm{L}$ nonfat dry milk, $10 \mathrm{~g} / \mathrm{L}$ bovine serum albumin, and $0.5 \mathrm{~g} / \mathrm{L} \mathrm{NaN}_{3}$ in $1 \times$ phosphate-buffered saline (PBS; $2.7 \mathrm{mM} \mathrm{KCl}, 1.5 \mathrm{mM} \mathrm{KH}_{2} \mathrm{PO}_{4}, 136 \mathrm{mM} \mathrm{NaCl}, 8 \mathrm{mM} \mathrm{Na}_{2} \mathrm{HPO}_{4}$ ) + 0.05\% (v/v) Tween 20] and incubated for 16 hours with one of the following primary antibodies: rabbit anti-PTEN (1:1000; Cell Signaling Technologies, Danvers, MA), rabbit anti-PO ${ }_{4}$ S380,T382, T383-PTEN (1:250; Cell Signaling), rabbit anti-PO 4 -T308/473-Akt (1:100, Cell Signaling), rabbit anti-PO 4 SMAD 1 [S463/465], 5[S463/465],8[S426/428] (1:1000, Cell Signaling). After washing six times in PBS $+0.05 \%$ Tween 20, the blots were incubated with goat anti-rabbit IgGs conjugated to horseradish peroxidase for one hour $(1: 200,000$ dilution, Pierce, Rockford, IL) in $2.5 \mathrm{~g} / \mathrm{L}$ nonfat dry milk, PBS, and $0.05 \%$ Tween 20. Peroxidase activity was detected via West Femto ${ }^{\circledR}$ chemiluminescence reagent as directed by the manufacturer (Pierce). Photo images were analyzed by densitometry and ratios of protein of interest to GAPDH were determined and compared between treatments.

\section{Doxacyclin-inducible PTEN expression}

pTetOn-PTEN or C4-2 control cells (described above) were plated at a density of 10,000 cells per well in 6 well plates (for protein expression analysis) or 5000 cells/well in 24-well plates (for growth analysis) and grown in 10\% FBS/ RPMI 1640 medium. Analysis of PTEN 
protein expression: after reaching $90 \%$ confluency, cells were treated with concentrations of doxacyclin (0.03-3.0 $\mu \mathrm{M}$ in semi-log increments) and either $10 \mathrm{ng} / \mathrm{ml} \mathrm{BMP-4}$ or vehicle (0.2\% BSA in PBS) overnight (16 hours). Cells were collected and protein was extracted and analyzed as described previously. Analysis of growth rate: 5000 cells were plated per well in 24-well plates and allowed to attach for 24 hours. Cells were then treated with concentrations of doxacyclin (0.03-3.0 $\mu \mathrm{M}$ in semi-log increments) and either $10 \mathrm{ng} / \mathrm{ml}$ BMP-4 or vehicle $(0.2 \%$ BSA in PBS) in 10\% FBS/RPMI 1640 medium. At time 0 and at 24 hour intervals, cell photos of each well were taken at consistent marked locations in quadruplicate. All cell growth experiments were performed 4 times $(n=4)$ for each cell line. Cell numbers were determined for each treatment and are reported as number of cells per $20 \mathrm{X}$ field. Each point is the mean \pm S.E.M. of the total cell counts.

\section{siRNA knockdown of PTEN expression}

Stable PTEN siRNA-expression clones of E6 and BPH-1 cell lines were generated using the Trans-Lentiviral ${ }^{\mathrm{TM}}$ GIPZ packaging system and Expression Arrest ${ }^{\mathrm{TM}}$ shRNAmir lentiviral delivery method using conditions and methods instructed by the manufacturer (Open Biosystems, Huntsville, AL). PTEN siRNA gene constructs employed human PTEN sequence clone RHS4430-99328837. Briefly, shRNA coding constructs supplied by Open Biosystems were cloned into pGIPZ expression plasmids (expressing selection factors puromycin resistance and GFP expression) using the protocol supplied and transformed into TLA-HEK293T packaging cells to generate live Lentivirus. After ampicillin selection of expressing clones, Lentiviral-producing packaging cells were grown and the lysed product was collected and used to infect prostate epithelial cell lines plated to 50\% confluency. After infection, epithelial cells were selected for expression by puromycin-resistance and sorted by flow cytometry for GFP expression to ensure gene transduction. Effective PTEN expression knockdown on the siRNA clones was confirmed by a minimum of $70 \%$ expression knockdown by immunoblotting. Growth rate and PTEN inducibility experiments were performed in these cells and those expressing a scrambled sequence siRNA previously shown not to effect gene expression by Open Biosystems.

\section{RT-PCR of mRNA levels}

Prostate cell lines were grown to $90 \%$ confluency in 12 well plates using cell line-specific conditions as described above and treated with either $10 \mathrm{ng} / \mathrm{ml} \mathrm{BMP-4}$ or vehicle $(0.02 \%$ BSA in PBS) for 2, 4, 8, or 24 hours. Cells were harvested in $350 \mu 1$ Qiagen RNeasy RLT lysis buffer plus 2-mercaptoethanol, RNA was extracted using the RNeasy kit as directed by the manufacturer (Qiagen, Valencia, CA), and complementary DNA was made using reverse transcription as previously described.[25] RT-PCR for PTEN expression was performed as published [24] using the following primers: S27 forward TCTTTAGCCATGCACAAACG; S27 reverse TTTCAGTGCTGCTTCCTCCT; PTEN forward GAAGACCATAACCCACCACA; PTEN reverse TACACCAGTCCGTCCCTTTC. Cycle to threshold was calculated as previously described, and expression of PTEN was calculated as a ratio to ribosomal S27 expression. Comparisons between groups were made with analysis of variance (ANOVA), with $\mathrm{p}<0.05$ indicative of significant difference.

\section{PTEN mRNA decay assay}

E6 prostate cell lines were grown to $80 \%$ confluency in 12 well plates using cell linespecific conditions as described above and treated with either $10 \mathrm{ng} / \mathrm{ml} \mathrm{BMP-4}$ or vehicle (0.02\% BSA in PBS) for 16 hours. Cells were then treated with $5 \mu \mathrm{M}$ actinomycin D, a transcriptional inhibitor. This concentration was shown to be optimal for inhibition of transcription in these cells in previous experiments. Separate wells of cells were harvested at time 0 and at $0.5,1,1.5,2,3,4,6,8$, and 24 hours after addition of actinomycin in $350 \mu 1$ Qiagen RNeasy RLT lysis buffer plus 2-mercaptoethanol, RNA was extracted using the 
RNeasy kit as directed by the manufacturer (Qiagen, Valencia, CA), and complementary DNA was made using reverse transcription as previously described.[25] RT-PCR for PTEN expression was performed using the method and primers described above. Cycle to threshold was calculated, expression ratio of PTEN to ribosomal S27 expression was calculated for each sample. The amount of PTEN for each time point was calculated as a ratio to that at time 0 , and a degradation curve was made and linear regression analysis performed (excel) to determine the half-life of each mRNA. Comparisons between BMP and vehicle-treated cells were made with analysis of variance (ANOVA) with $\mathrm{p}<0.05$ indicative of significant difference.

\section{PTEN protein stability assay}

E6 prostate cell lines were grown to $80 \%$ confluency in 6 well plates using cell line-specific conditions as described above and treated with either $10 \mathrm{ng} / \mathrm{ml} \mathrm{BMP}-4$ or vehicle $(0.02 \%$ BSA in PBS) for 16 hours. Cells were then treated with $1 \mu \mathrm{M}$ cyclohexamide, a translational inhibitor. This concentration was shown to be optimal for inhibition of translation in these cells in preliminary experiments. Separate wells were harvested at time 0 and at 1, 2, 4, 8, 24 , and 48 hours after addition of cyclohexamide in protease inhibitor-containing lysis buffer. Protein was extracted and immunoblotting for PTEN and GAPDH was performed for each sample as described above. The protein expression ratio of PTEN to GAPDH was calculated for each sample. The amount of PTEN for each time point was calculated as a ratio to that at time 0 , and a degradation curve was made and linear regression analysis performed (excel) to determine the half-life of PTEN protein. Comparisons between BMP and vehicle-treated cells were made with analysis of variance (ANOVA) with $\mathrm{p}<0.05$ indicative of significant difference.

\section{RESULTS}

We treated E6 and BPH-1 prostate epithelial cells with a concentration-response curve to BMP-4 and measured its effect on growth rate and PTEN protein expression. BMP-4 inhibited proliferation of E6 and BPH-1 cells in a concentration-dependent manner [Figure $1]$ and this inhibitory effect correlated with BMP-induced PTEN protein expression. Treatment with BMP-4 significantly induced expression of PTEN protein in E6 (6-fold) and BPH-1 (2.5-fold). [Figure 2] This induction was concentration-dependent; the maximal effect in both cell lines was observed from treatment with $10 \mathrm{ng} / \mathrm{ml}$ BMP-4. Induction of canonical BMP signaling was confirmed by determination of activated (phosphorylated) SMAD (isoforms 1, 5, 8). BMP-4 treatment and the associated induction of PTEN reduced $\mathrm{PI}_{3} \mathrm{~K}$-Akt signaling as evidenced by decreased phosphorylation of Akt (serine 473): BMP-4 reduced activated Akt by $39( \pm 12) \%$ in E6 cells, and by $33( \pm 14) \%$ in BPH-1 cells. [Figure 2C]. Since the effect of BMP on colon cancer cells was mediated by activation of the Erk-MAP kinase pathway,[21] we investigated Erk pathway activation by phosphorylation of Erk in response to BMP in prostate epithelial cells. While Erk is highly active in these cells endogenously, we failed to demonstrate further activation of Erk in response to BMP. [Figure 2D] Both the induction of PTEN and inhibition of proliferation by BMP-4 were completely blocked by the BMP antagonist NOGGIN.

The LNCaP prostate cancer cell line is generally considered to be PTEN negative and no induction of PTEN expression or change in Akt activation was observed in LNCaP cells treated with BMP-4 (data not shown). Overexpression of PTEN in LNCaP-derived C4-2 cells consistently reduces proliferation, suggesting that PTEN activation is sufficient to inhibit growth. C4-2 cells engineered to express active PTEN from a doxacyclin-driven promoter exhibit a concentration-dependent inhibition of cell proliferation by doxacyclin. [26] We treated these cells with increasing concentrations of doxacyclin in semi-log increments in the presence or absence of $10 \mathrm{ng} / \mathrm{ml} \mathrm{BMP}-4$ to examine the interaction of 
BPM-4 and PTEN [Figure 3A]. BMP-4 did not inhibit proliferation of cells lacking significant promoter-driven PTEN expression ( 0 to $0.1 \mathrm{mg} / \mathrm{ml}$ doxacyclin). Intermediate concentrations of doxacyclin $(0.3 \mu \mathrm{g} / \mathrm{ml}$ and $1.0 \mu \mathrm{g} / \mathrm{ml}$ doxacyclin) produced partial growth inhibition that was significantly augmented by BMP treatment as evidenced by a log-fold leftward shift in the concentration-response curve. However, cells lacking significant promoter-driven PTEN expression (0 to $0.1 \mathrm{mg} / \mathrm{ml}$ doxacyclin) did not respond to BMP, and BMP failed to produce further growth inhibition in cells with full PTEN promoter-driven expression ( $3 \mathrm{mg} / \mathrm{ml}$ doxacyclin). The effect of BMP on growth inhibition was mirrored by PTEN protein induction. [Figure 3B] These data indicate that partial promoter-driven PTEN expression is necessary for BMP-4 to significantly affect growth rate in C4-2 cells.

We next sought to determine if the growth inhibitory effects of BMP-4 are dependent upon PTEN. Transfection of E6, and BPH-1 cells with an siRNA construct, producing a minimum of 70\% expression knockdown, abrogated BMP-mediated growth inhibition [Figure 4A]. Transfection of the cells with PTEN siRNA not only rendered the cells refractory to BMPmediated inhibition, but also doubled the overall growth rate of these cells. Of note, the effect of transfecting both E6 and BPH-1 cells with the Lenti-viral methods described also had a negative effect on growth rate, as cells transduced by Lentivirus bearing a scrambled sequence had a decreased growth rate relative to untransfected controls. BMP signaling was unaffected, as evidenced by SMAD 1, 5, 8 phosphorylation, but $\mathrm{PI}_{3} \mathrm{~K}$-Akt signaling activity was increased. PTEN knockdown increased basal Akt phosphorylation 2.1-fold (ratio to GAPDH 0.12 controls; 0.25 siRNA-PTEN; $\mathrm{p}=0.02, \mathrm{n}=4$ ) in E6 cells and by $60 \%$ in $\mathrm{BPH}-1$ cells (ratio to GAPDH 0.61 controls; 1.11 siRNA-PTEN; $\mathrm{p}=0.05$, $n-4$ ). PTEN knockdown clearly abrogated the decrease in Akt phosphorylation by BMP-4. [Figure 4B] Non-silencing scrambled siRNA constructs had no effect on BMP-mediated growth inhibition. (not shown) PTEN knockdown had an expected measurable inductive effect on $\mathrm{PI}_{3} \mathrm{~K}$-Akt signaling as measured by phosphorylated Akt. These data indicate that the growth-slowing effect of BMP-4 on prostate cell lines is at least in part due to its ability to induce PTEN expression.

We next sought to determine if the effect of BMP-4 on PTEN expression is transcriptional, post-transcriptional, or translational, or post-translation. E6 cells treated with BMP-4 exhibit time-dependent induction of PTEN mRNA levels, with significant induction evident at 8 hours of treatment. [Figure 5A] This is not associated with an increase in mRNA stability for PTEN message, indicating that BMP-4 is likely inducing PTEN at the transcriptional level. In addition, BMP-4 treatment is associated with a rapid decrease in phosphorylated PTEN protein levels (residues 380, 382, and 383), despite an evident increase in total PTEN levels. [Figure 5C]. To investigate the effect of BMP treatment on PTEN protein stability, we treated E6 cells pre-exposed to either BMP-4 or vehicle with cyclohexamide $(5 \mu \mathrm{M})$ for $0,0.5,1,1.5,2,3,4,8$, or 24 hours and measured PTEN protein levels. We found that 24 hours of BMP pretreatment caused a doubling in PTEN half-life (15.1 hours to 28.4 hours, $\mathrm{p}=0.03, \mathrm{n}=4$ ). [Figure 5D] These data indicate that BMP-4 has a dual effect on PTEN expression that involves increased expression and enhanced protein stability.

\section{DISCUSSION}

To our knowledge, this is the first paper to report on the mechanism by which bone morphogenetic proteins mediate prostate cell proliferation rates. The data indicate that treatment of prostate cell lines with BMP-4 results in increased cellular PTEN concentrations and a corresponding decrease in $\mathrm{PI}_{3} \mathrm{~K}-\mathrm{Akt}$ signaling. The data further show that PTEN increase is at least in part responsible for the decreased proliferation rate observed in prostate cell lines since siRNA knockdown of PTEN expression attenuates BMP-mediated decreases in cellular proliferation. PTEN increase involves both transcriptional and post-translational mechanisms, as a rapid increase in PTEN mRNA and 
an increase in PTEN protein stability were observed after BMP-4 treatment. Experiments with conditional PTEN over-expressing cell lines further support a role for PTEN stability in cellular proliferation, as these cells required previous promoter-driven PTEN expression in order to respond to BMP-4 by PTEN expression increases and decreases in proliferation. Further, a decrease in phosphorylation of PTEN at residues 380, 382, and 383 are suggestive of enhanced PTEN activity, as these residues have been implicated in enzymatic activity in previous reports.[27] Future studies should be directed toward detailing the enzymatic effects of BMP signaling on PTEN function.

The BMP signaling pathway has critical roles in embryogenesis, organogenesis, cell growth, differentiation, cell migration and cell death.[28] Due to the diversity of these biological functions, it is not surprising that BMPs have been associated with control of proliferation and differentiation in normal and malignant prostate epithelial cells.[2,13,15] BMP-4 and BMP-7 are androgen-regulated genes that play critical roles in the proper regulation of prostate development by inhibiting epithelial proliferation, ductal budding and branching. [12] Specifically, BMP signaling is believed to promote differentiation of prostate epithelial cells, thereby repressing proliferative capacity.[12,29] In addition, the BMP antagonist Noggin is expressed in the developing mouse prostate and neutralizes inhibition of epithelial proliferation by BMP4 allowing ductal budding and regulation of bud outgrowth.[29] Our data suggest that in depth study of a possible interplay of BMP and PTEN / $\mathrm{PI}_{3} \mathrm{~K}$-Akt signaling is warranted to further the mechanistic understanding of BMP signaling in prostate development.

With regard to prostate cancer however, divergence in expression and function among the BMPs is evident in published reports and there are considerable inconsistencies in published results regarding the biological function of BMPs in prostate cancer cells. For example, BMP-6 expression is upregulated in prostate cancers relative to noncancerous epithelium, [30] while BMP-2, BMP-4, and BMP-7 expression is decreased.[31] Yet, BMP-4, BMP-6 and BMP-7 have all been consistently detected in prostate cancer bone metastases and expression of proteins involved in the BMP signaling pathway are often observed in metastatic prostate cancer.[32] While several reports show a growth-reducing and differentiating effect of BMPs similar to what occurs in prostate development, other findings support a tumor-promoting role.[33-34] These inconsistencies illustrate a pronounced uncertainty in this field, and the data presented in this manuscript may contribute to resolving some of these uncertainties. Specifically, the PTEN status of a particular tumor may be critical in determining how that tumor may respond to BMP expression: a PTENpositive cell may respond in growth inhibitory/pro-differentiation direction while a PTENnegative cell may respond in the opposite direction.

Invasion and migration are processes of particular interest regarding BMP signaling in prostate cancer. Yang et al have reported that BMP-7 increased invasiveness and migration on PC-3 cells, [33] yet Feeley et al. reported no effects of BMP-7 on migration or invasion of these same cells.[35] Dai et al showed that BMP-7 (and BMP-2/4) did not alter invasion and migration of LuCaP and C4-2B cells.[36] Yet, Ye et al have reported that inhibition of BMP-7 expression in PC-3 cells increases the invasive potential and migration of cells while reducing their proliferation.[34] This process was dependent upon the loss of BMP signaling antagonists noggin and follistatin. It would be interesting to know how PTEN expression affects the results in this model, and future studies should be directed at determining if BMP-mediated invasion and metastasis of high-grade prostate cancer cells is modulated by the PTEN-Akt pathway.

While it is well-established that PTEN loss of function or suppression of expression is associated with prostate cancer growth and progression, recent papers have begun to define 
a role for PTEN in prostate cell migration and metastases.[26] Cell migration in PTENnegative C4-2 cells is inhibited by ectopic PTEN expression and is dependent upon activity of the lipid phosphatase function of PTEN and corresponding decrease in $\mathrm{PI}_{3} \mathrm{~K}-\mathrm{Akt}$ signaling.[24] Similarly, PTEN-deficient cells exhibit increased cell motility, and $\mathrm{PI}_{3} \mathrm{~K}$-Akt signaling plays an important role in the regulation and directionality of cell migration.[37] In addition, bladder cancer cells exhibit $\mathrm{PI}_{3} \mathrm{~K}$-Akt-dependent epidermal growth factor-mediated chemotaxis.[38-39] Our data demonstrate that BMP signaling, known to play a critical role in cell migration and metastases, regulates PTEN expression. This further implicates PTEN expression status of the tumor as a possible intermediary factor in how a tumor responds to BMP, and may explain inconsistencies in the literature involving prostate cancer responses to BMP signaling.

Our work shows that a strong signaling interrelationship exists between two signaling molecules known to be lost or down-regulated during prostate cancer growth and progression: the BMP and PTEN pathways. BMP-4 causes the induction of PTEN expression in prostate epithelial cells and is involved in stabilizing PTEN protein, resulting in significantly increased PTEN protein levels and the slowing of cell proliferation. In addition, previously published reports have implicated BMP signaling and the PI3K/Akt pathway in cell migration and metastases of prostate tumors, therefore future studies regarding the effect of BMP mediated PTEN expression on these critical processes should yield interesting results. Further future studies modulating both the BMP and PTEN pathways may have clinical relevance in the understanding and treatment of prostate cancer.

\section{Acknowledgments}

Funding: Department of Defense Prostate Cancer Program award W81XWH-07-1-0092. T.J.J. was also funded by the Department of Molecular and Environmental Toxicology through training grant from the National Institute of Environmental health Sciences (NIEHS), T32ES007015.

\section{REFERENCES}

1. Sircar K, Yoshimoto M, Monzon FA, Koumakpayi IH, Katz RL, Khanna A, Alvarez K, Chen G, Darnel AD, Aprikian AG, Saad F, Bismar TA, Squire JA. PTEN genomic deletion is associated with p-Akt and AR signalling in poorer outcome, hormone refractory prostate cancer. J Pathol. 2009; 8(4):505-513. [PubMed: 19402094]

2. Cantley LC, Neel BG. New insights into tumor suppression: PTEN suppresses tumor formation by restraining the phosphoinositide 3-kinase/AKT pathway. Proc Natl Acad Sci U S A. 1999; 96(8): 4240-4245. [PubMed: 10200246]

3. Groszer M, Erickson R, Scripture-Adams DD, Lesche R, Trumpp A, Zack JA, Kornblum HI, Liu X, $\mathrm{Wu} \mathrm{H}$. Negative regulation of neural stem/progenitor cell proliferation by the Pten tumor suppressor gene in vivo. Science. 2001; 294:2186-2189. [PubMed: 11691952]

4. Halvorsen OJ, Haukaas SA, Akslen LA. Combined loss of PTEN and p27 expression is associated with tumor cell proliferation by Ki-67 and increased risk of recurrent disease in localized prostate cancer. Clin Cancer Res. 2003; 9(4):1474-1479. [PubMed: 12684422]

5. Frost RA, Lang CH. Protein kinase B/Akt: a nexus of growth factor and cytokine signaling in determining muscle mass. J Appl Physiol. 2007; 103(1):378-387. [PubMed: 17332274]

6. Arcaro A, Aubert M, Espinosa del Hierro ME, Khanzada UK, Angelidou S, Tetley TD, Bittermann AG, Frame MC, Seckl MJ. Critical role for lipid raft-associated Src kinases in activation of PI3KAkt signalling. Cell Signal. 2007; 19(5):1081-1092. [PubMed: 17275257]

7. Xia H, Nho RS, Kahm J, Kleidon J, Henke CA. Focal adhesion kinase is upstream of phosphatidylinositol 3-kinase/Akt in regulating fibroblast survival in response to contraction of type I collagen matrices via a beta 1 integrin viability signaling pathway. J Biol Chem. 2004; 279(31): 33024-33034. [PubMed: 15166238] 
8. Ozes ON, Akca H, Mayo LD, Gustin JA, Maehama T, Dixon JE, Donner DB. A phosphatidylinositol 3-kinase/Akt/mTOR pathway mediates and PTEN antagonizes tumor necrosis factor inhibition of insulin signaling through insulin receptor substrate-1. Proc Natl Acad Sci USA. 2001; 98(8):4640-4645. [PubMed: 11287630]

9. Prins GS, Putz O. Molecular signaling pathways that regulate prostate gland development. Differentiation. 2008; 76(6):641-659. [PubMed: 18462433]

10. Gazzerro E, Canalis E. Bone morphogenetic proteins and their antagonists. Rev Endocr Metab Disord. 2006; 7:51-65. [PubMed: 17029022]

11. Lamm ML, Podlasek CA, Barnett DH, Lee J, Clemens JQ, Hebner CM, Bushman W. Mesenchymal factor bone morphogenetic protein 4 restricts ductal budding and branching morphogenesis in the developing prostate. Dev Biol. 2001; 232:301-314. [PubMed: 11401393]

12. Grishina IB, Kim SY, Ferrara C, Makarenkova HP, Walden PD. BMP7 inhibits branching morphogenesis in the prostate gland and interferes with Notch signaling. Dev Biol. 2005; 288(2): 334-347. [PubMed: 16324690]

13. Miyazaki H, Watabe T, Kitamura T, Miyazono K. BMP signals inhibit proliferation and in vivo tumor growth of androgen-insensitive prostate carcinoma cells. Oncogene. 2004; 23(58):93269335. [PubMed: 15531927]

14. Brubaker KD, Corey E, Brown LG, Vessella RL. Bone morphogenetic protein signaling in prostate cancer cell lines. J Cell Biochem. 2004; 91(1):151-160. [PubMed: 14689587]

15. Kim IY, Lee DH, Lee DK, Ahn HJ, Kim MM, Kim SJ, Morton RA. Loss of expression of bone morphogenetic protein receptor type II in human prostate cancer cells. Oncogene. 2004; 23(46): 7651-7659. [PubMed: 15354178]

16. Tamguney T, Stokoe D. New insights into PTEN. J Cell Sci. 2007; 120:4071-4079. [PubMed: 18032782]

17. Engin H, Baltali E, Güler N, Güler G, Tekuzman G, Uner A. Expression of PTEN, cyclin D1, P27/ KIP1 in invasive ductal carcinomas of the breast and correlation with clinicopathological parameters. Bull Cancer. 2006; 93(2):E21-E26. [PubMed: 16517411]

18. Li DM, Sun H. TEP1, encoded by a candidate tumor suppressor locus, is a novel protein tyrosine phosphatase regulated by transforming growth factor beta. Cancer Res. 1997; 57:2124-2129. [PubMed: 9187108]

19. Stiles BL. Phosphatase and tensin homologue deleted on chromosome 10: extending its PTENtacles. Int J Biochem Cell Biol. 2009; 41(4):757-761. [PubMed: 18950730]

20. Waite KA, Eng C. BMP2 exposure results in decreased PTEN protein degradation and increased PTEN levels. Hum Mol Genet. 2003; 12(6):679-684. [PubMed: 12620973]

21. Beck SE, Carethers JM. BMP suppresses PTEN expression via RAS/ERK signaling. Cancer Biol Ther. 2007; 6(8):1313-1317. [PubMed: 18059158]

22. Schwarze SR, DePrimo SE, Grabert LM, Fu VX, Brooks JD, Jarrard DF. Novel pathways associated with bypassing cellular senescence in human prostate epithelial cells. J Biol Chem. 2002; 277(17):14877-14883. [PubMed: 11836256]

23. Hayward SW, Dahiya R, Cunha GR, Bartek J, Deshpande N, Narayan P. Establishment and characterization of an immortalized but non-transformed human prostate epithelial cell line: BPH-1. In Vitro Cell Dev Biol Anim. 1995; 31(1):14-24. [PubMed: 7535634]

24. Wu Z, Conaway M, Gioeli D, Weber MJ, Theodorescu D. Conditional expression of PTEN alters the androgen responsiveness of prostate cancer cells. Prostate. 2006; 66(10):1114-1123. [PubMed: 16637073]

25. Jerde TJ, Bushman W. IL-1 induces IGF-dependent epithelial proliferation in prostate development and reactive hyperplasia. Sci Signal. 2009; 2(86):ra49. [PubMed: 19724062]

26. Wu Z, McRoberts KS, Theodorescu D. The role of PTEN in prostate cancer cell tropism to the bone micro-environment. Carcinogenesis. 2007; 28(7):1393-1400. [PubMed: 17347137]

27. Rahdar M, Inoue T, Meyer T, Zhang J, Vazquez F, Devreotes PN. A phosphorylation-dependent intramolecular interaction regulates the membrane association and activity of the tumor suppressor PTEN. Proc Natl Acad Sci USA. 2009; 106(2):480-485. [PubMed: 19114656] 
28. Miyazaki Y, Oshima K, Fogo A, Ichikawa I. Evidence that bone morphogenetic protein 4 has multiple biological functions during kidney and urinary tract development. Kidney Int. 2003; 63(3):835-844. [PubMed: 12631064]

29. Cook C, Vezina CM, Allgeier SH, Shaw A, Yu M, Peterson RE, Bushman W. Noggin is required for normal lobe patterning and ductal budding in the mouse prostate. Dev Biol. 2007; 312(1):217230. [PubMed: 18028901]

30. Darby S, Cross SS, Brown NJ, Hamdy FC, Robson CN. BMP-6 over-expression in prostate cancer is associated with increased Id-1 protein and a more invasive phenotype. J Pathol. 2008; 214(3): 394-404. [PubMed: 18072288]

31. Masuda H, Fukabori Y, Nakano K, Shimizu N, Yamanaka H. Expression of bone morphogenetic protein-7 (BMP-7) in human prostate. Prostate. 2004; 59(1):101-106. [PubMed: 14991870]

32. Feeley BT, Gamradt SC, Hsu WK, Liu N, Krenek L, Robbins P, Huard J, Lieberman JR. Influence of BMPs on the formation of osteoblastic lesions in metastatic prostate cancer. J Bone Miner Res. 2005; 20(12):2189-2199. [PubMed: 16294272]

33. Yang S, Zhong C, Frenkel B, Reddi AH, Roy-Burman P. Diverse biological effect and Smad signaling of bone morphogenetic protein 7 in prostate tumor cells. Cancer Res. 2005; 65(13): 5769-5777. [PubMed: 15994952]

34. Ye L, Lewis-Russell JM, Kynaston H, Jiang WG. Endogenous bone morphogenetic protein-7 controls the motility of prostate cancer cells through regulation of bone morphogenetic protein antagonists. J Urol. 2007; 178:1086-1091. [PubMed: 17644136]

35. Feeley BT, Krenek L, Liu N, Hsu WK, Gamradt SC, Schwarz EM, Huard J, Lieberman JR. Overexpression of noggin inhibits BMP-mediated growth of osteolytic prostate cancer lesions. Bone. 2006; 38(2):154-166. [PubMed: 16126463]

36. Dai J, Keller J, Zhang J, Lu Y, Yao Z, Keller ET. Bone morphogenetic protein-6 promotes osteoblastic prostate cancer bone metastases through a dual mechanism. Cancer Res. 2005; 65(18): 8274-8285. [PubMed: 16166304]

37. Shukla S, Maclennan GT, Hartman DJ, Fu P, Resnick MI, Gupta S. Activation of PI3K-Akt signaling pathway promotes prostate cancer cell invasion. Int J Cancer. 2007; 121(7):1424-1432. [PubMed: 17551921]

38. Gu J, Tamura M, Pankov R, Danen EH, Takino T, Matsumoto K, Yamada KM. Shc and FAK differentially regulate cell motility and directionality modulated by PTEN. J Cell Biol. 1999; 146(2):389-403. [PubMed: 10427092]

39. Theodorescu D, Laderoute KR, Gulding KM. Epidermal growth factor receptor-regulated human bladder cancer motility is in part a phosphatidylinositol 3-kinase-mediated process. Cell Growth Differ. 1998; 9(11):919-928. [PubMed: 9831244] 


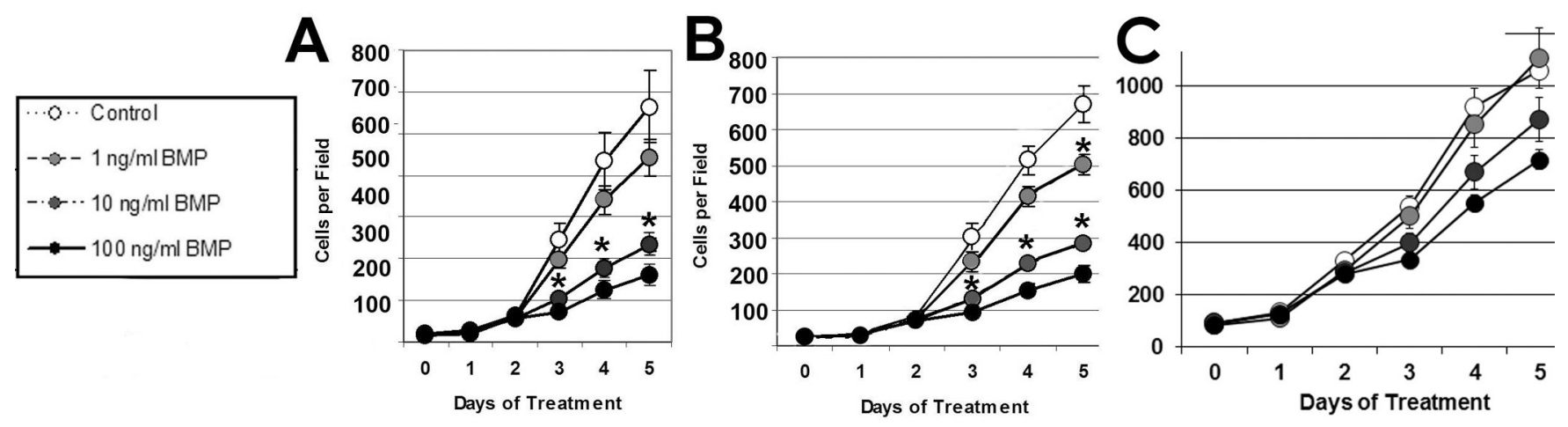

Figure 1.

BMP-4 slows the growth of prostate cell lines. Growth curves of E6 (A.), BPH-1 (B.) and parental LNCaP (C.) treated with vehicle (0.1\% BSA), $1 \mathrm{ng} / \mathrm{ml}$ BMP-4, $10 \mathrm{ng} / \mathrm{ml} \mathrm{BMP-4,}$ and $100 \mathrm{ng} / \mathrm{ml} \mathrm{BMP-4}$. Quantification reflects the number of cells per 20× field; data reflect the mean of 4 experiments with 4 determinations averaged in each experiment. Statistical considerations: * p<0.05 BMP-4 versus vehicle, ANOVA. 

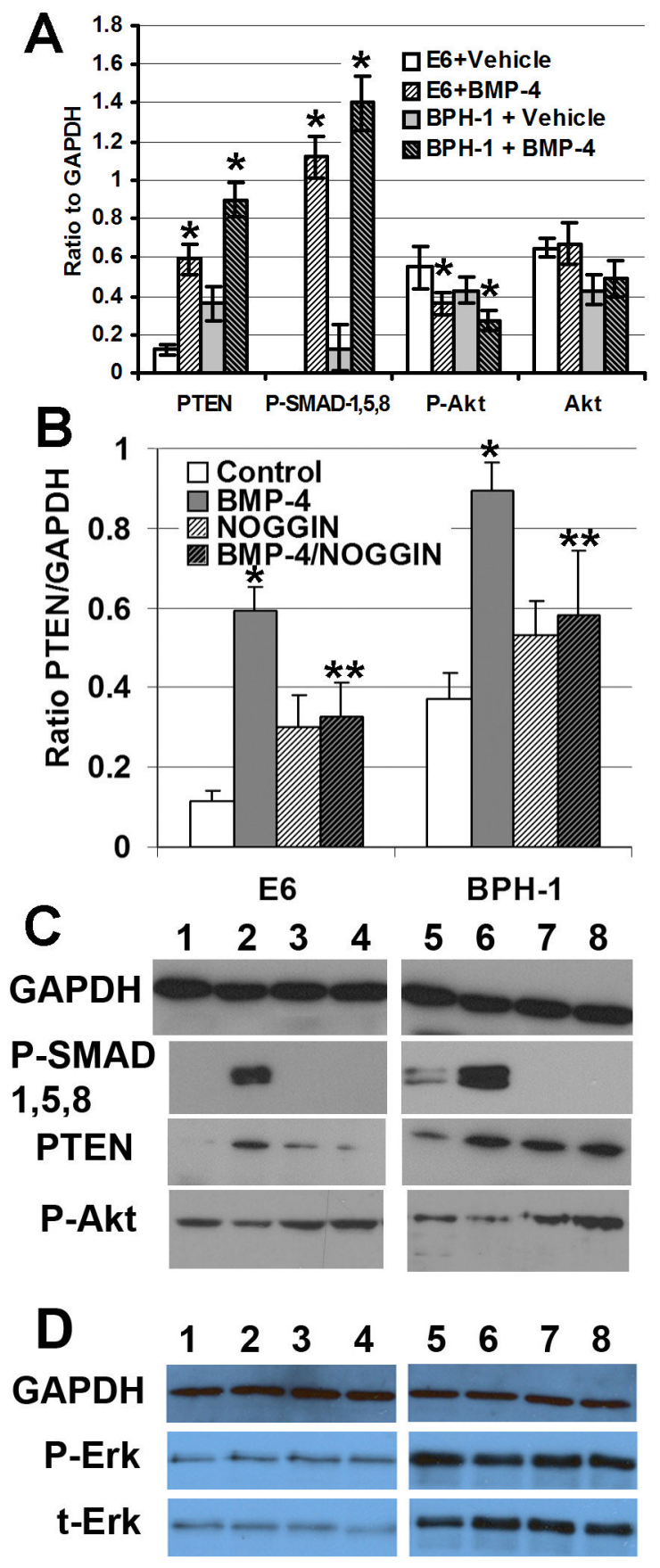

Figure 2.

BMP treatment of prostate epithelial cell lines increases PTEN protein expression. A. Quantified data from immunoblots from 4 experiments: $10 \mathrm{ng} / \mathrm{ml}$ BMP-4 induced PTEN expression in E6 and BPH-1 cells, resulting in suppressed $\mathrm{PI}_{3} \mathrm{~K}$-Akt signaling, as measured by phosphorylated T308/S472 Akt. Data presented are mean $+/-$ sem. Statistical considerations: * $\mathrm{p}<0.05$ BMP-4 versus vehicle. B. Quantified data from immunoblots from 4 experiments; data presented are mean $+/-$ sem. Statistical considerations: $* \mathrm{p}<0.05$ BMP-4 versus vehicle; ** $\mathrm{p}<0.05 \mathrm{BMP}-4+$ Noggin versus BMP alone, analysis of variance (ANOVA). C. Immunoblots of prostate cells (1-4, E6; 5-8, BPH-1) treated with either vehicle (0.1\% BSA, lanes 1, 5), $10 \mathrm{ng} / \mathrm{ml} \mathrm{BMP-4}$ (lanes 2, 6), $100 \mathrm{ng} / \mathrm{ml}$ Noggin (lanes 3, 7), 
and BMP-4 pre-incubated (30 minutes) with Noggin (lanes 4, 8). D. Immunoblots of prostate cells (1-4, E6; 5-8, BPH-1) blotted for activation of the Erk-MAP kinase pathway as indicated by Phospho-S140, T142 Erk. GAPDH (loading control) and total Erk are also shown. Cell protein extracts were loaded in the identical pattern as in C. 


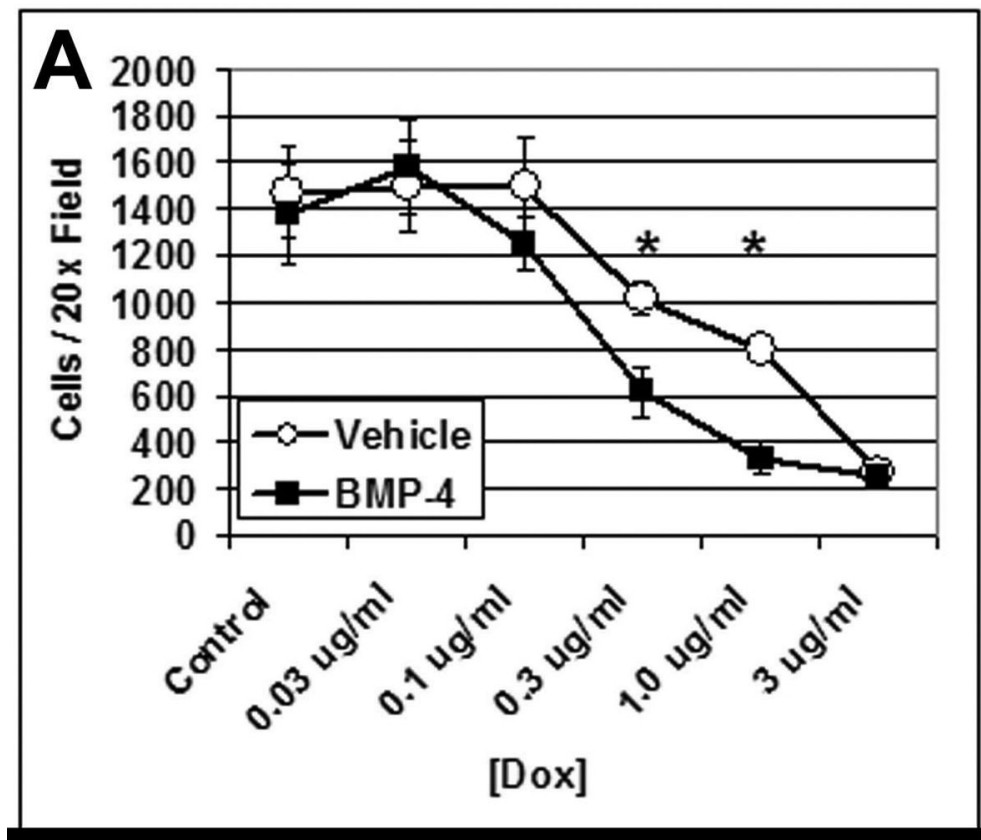

B

[Doxacyclin $(\mu \mathrm{M})$

$\begin{array}{llllll}0 & 0.03 & 0.1 & 0.3 & 1.0 & 3.0\end{array}$

GAPDH

Veh

PTEN

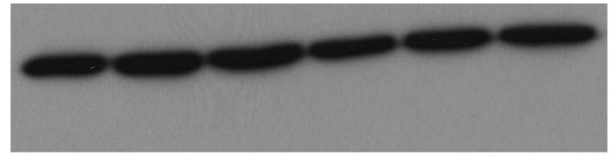

\section{BMP}

GAPDH

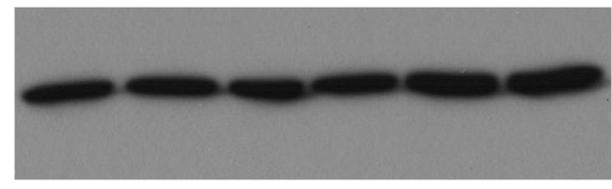

\section{PTEN}

Figure 3.

BMP-4 exerts PTEN-dependent effects on C4-2 growth. PTEN negative C4-2 cells were engineered to express a doxacyclin (dox)-inducible PTEN gene in which PTEN expression is dose-dependently induced by dox. Cells with little or no PTEN induction by dox were unable to respond to BMP-4 by either cell growth inhibition [A] or PTEN protein expression. [B] However, upon moderate dox stimulation (0.1-1.0 $\mu \mathrm{g} / \mathrm{ml}$ dox $)$, BMP-4 repressed growth and enhanced PTEN expression. 


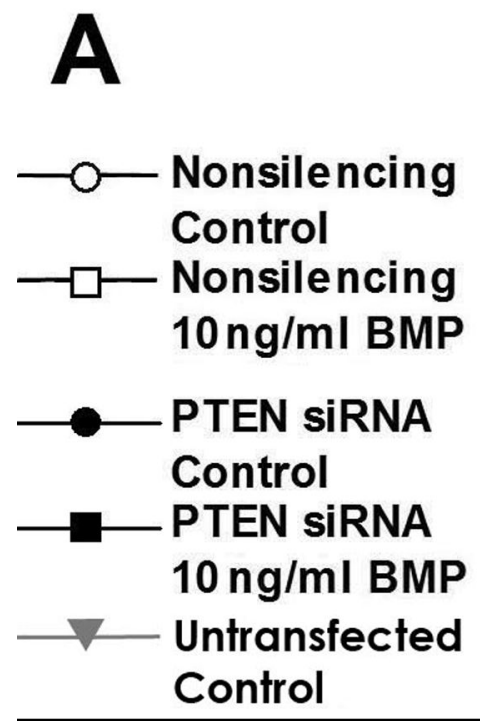

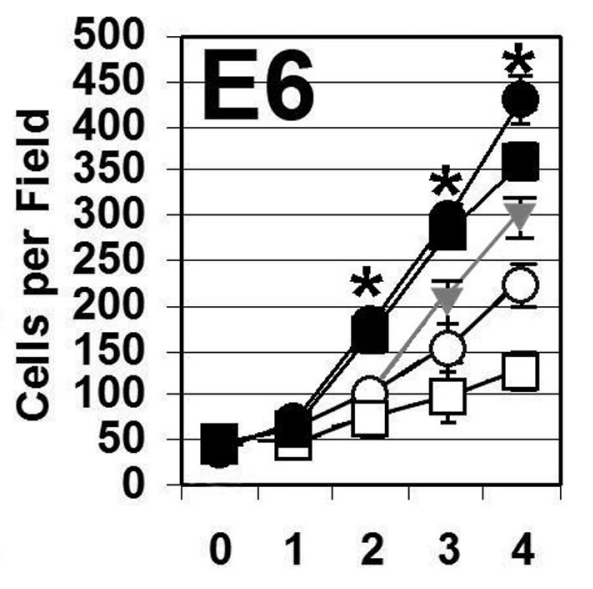

Days of Treatment

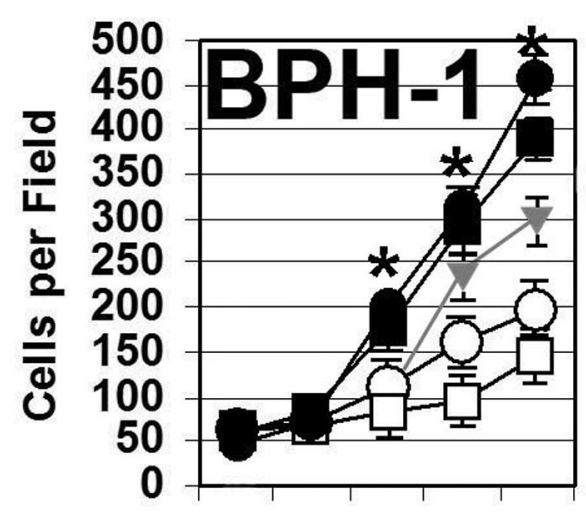

$\begin{array}{lllll}0 & 1 & 2 & 3 & 4\end{array}$

Days of Treatment
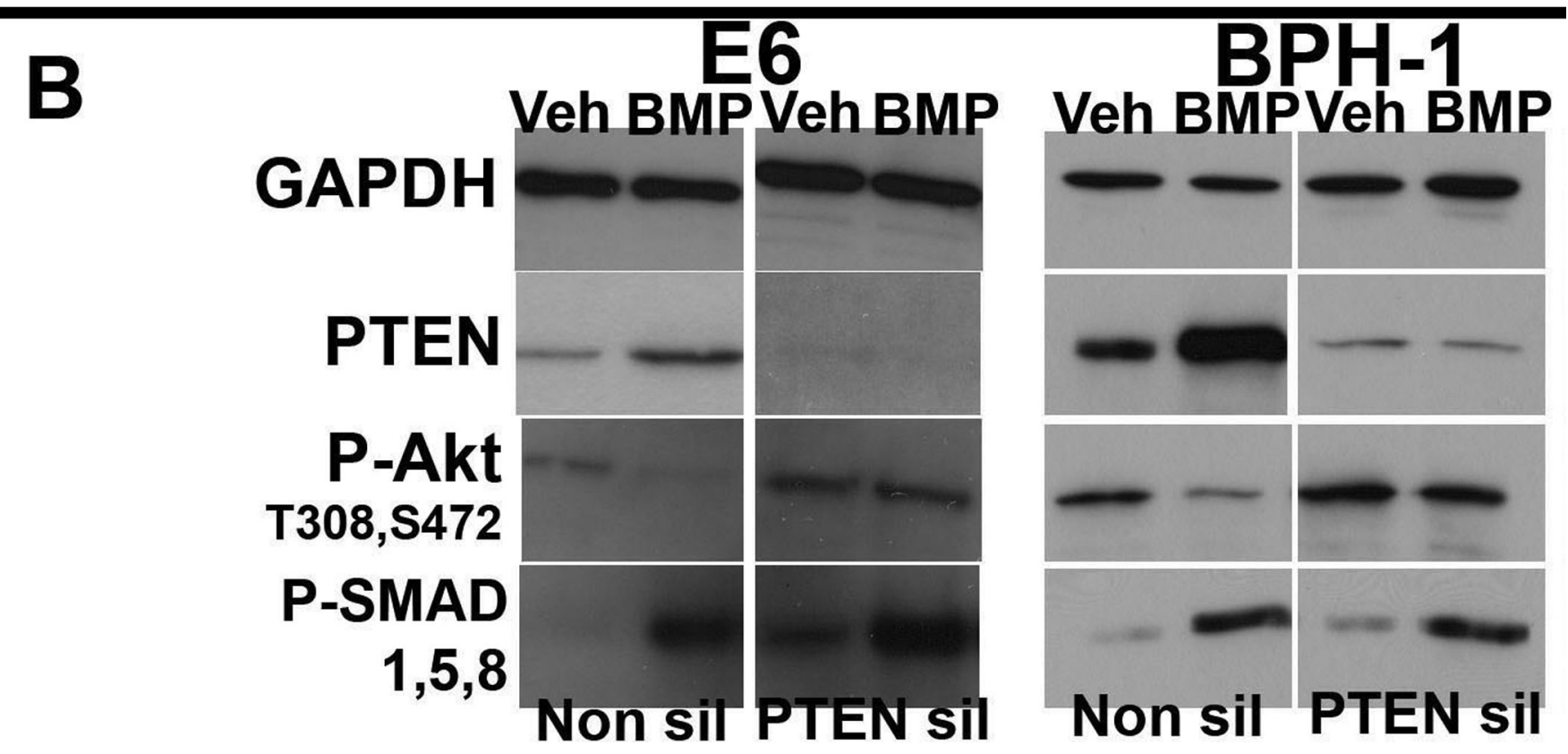

Figure 4.

BMP-4 repressed cell growth in prostate epithelial cells is dependent on PTEN expression. [A] BMP-4 was unable to fully repress growth of E6, and BPH-1 stably transfected with siRNA constructs against PTEN relative to cells transfected with a scrambled non-silencing siRNA. Expression of the siRNA construct itself caused a substantial induction in growth rate further demonstrating the importance of PTEN in controlling growth rate in prostate epithelial cells. Data presented reflect the number of cells per $20 \times$ field; data presented are the mean of 4 experiments with 4 determinations averaged in each experiment. Statistical considerations: * p<0.05 BMP-4 versus vehicle, ANOVA. [B] siRNA knockdown of PTEN prevented BMP-mediated induction of PTEN expression and inactivation of Akt signaling, as determined by immunoblotting. Activation of SMAD signaling is unaffected, demonstrating that the BMP signaling axis remains intact in PTEN siRNA-transfected cells. 

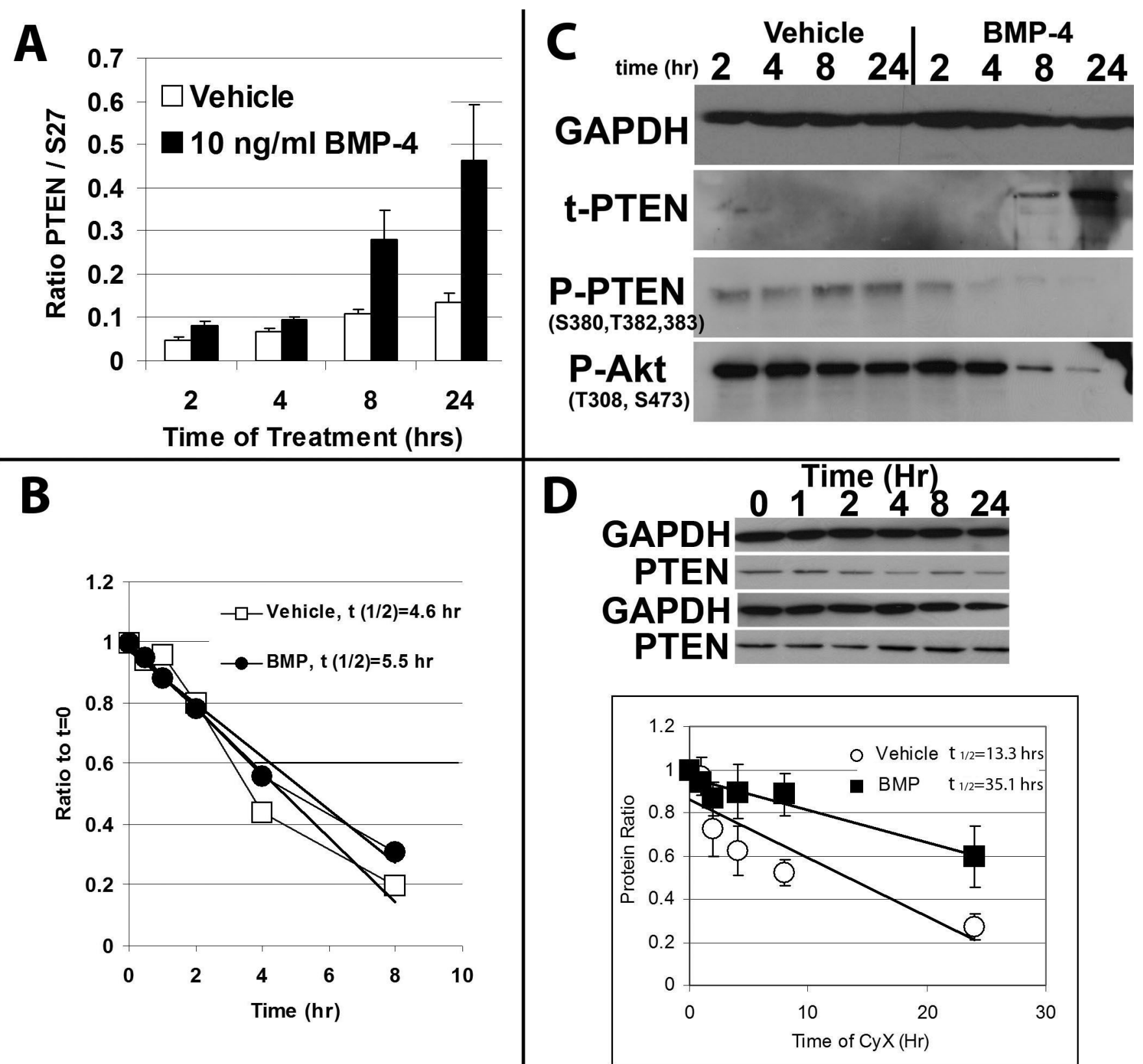

Figure 5.

BMP-4 sustains PTEN protein expression in prostatic epithelial cells post-translationally by reducing PTEN protein degradation. [A] BMP-4 treatment of E6 cells induces PTEN mRNA expression gradually over 24 hours of treatment as determined by RT-PCR. BMP-4 treatment had no effect on PTEN mRNA stability, as determined by actinomycin D treatment [B]. However, BMP treatment of E6 cells causes a marked reduction in phosphorylated PTEN (P-S380, T382/383 PTEN) despite increasing amounts of total PTEN (t-PTEN) [C], suggesting that PTEN protein conformation and activity may be affected by BMP. PTEN protein stability is significantly enhanced by BMP-4 treatment as determined 
by cyclohexamide treatment [D]. Inhibition of the $26 \mathrm{~S}$ proteosome with $10 \mu \mathrm{M}$ MG-132 results in similar protein stabilization effects on PTEN (not shown). 